Correction

\title{
Correction: Thabet, H.; Kendre, S.; Chalishajar, D. New Analytical Technique for Solving a System of Nonlinear Fractional Partial Differential Equations Mathematics 2017, 5, 47
}

\author{
Hayman Thabet ${ }^{1}{ }^{(\mathbb{D})}$, Subhash Kendre ${ }^{2}$ and Dimplekumar Chalishajar ${ }^{2, *}$ \\ 1 Department of Mathematics, Savitribai Phule Pune University, Pune 411007, India; \\ haymanthabet@gmail.com \\ 2 Department of Applied Mathematics, Virginia Military Institute, Lexington, VA 24450, USA; \\ dipu17370@gmail.com \\ * Correspondence: sdkendre@yahoo.com
}

Received: 13 February 2018; Accepted: 14 February 2018; Published: 14 February 2018

We have found some errors in the caption of Figure 1 and Figure 2 in our paper [1], and thus would like to make the following corrections:

On page 10, the caption of Figure 1 should be changed from:

Figure 1. (a) The graph for the approximate solution of Example 1 for $\alpha=\beta=0.5, \gamma=1$ and $q=1$; (b) The graph for the exact solution of Example 1 for $\alpha=\beta=0.5$ and $\gamma=1$.

To the following correct version:

Figure 1. (a) The graph for the approximate solution of Example 2 for $\alpha=\beta=0.5$ and $q_{1}=q_{2}=1$; (b) The graph for the exact solution of Example 2 for $\alpha=\beta=0.5$.

Furthermore, on page 13, the caption of Figure 2 should be changed from:

Figure 2. (a) The graph for the approximate solution of Example 2 for $\alpha=\beta=0.5$ and $q_{1}=q_{2}=1$; (b) The graph for the exact solution of Example 2 for $\alpha=\beta=0.5$.

To the following correct version:

Figure 2. (a) The graph for the approximate solution of Example 1 for $\alpha=\beta=0.5, \gamma=1$ and $q=1$; (b) The graph for the exact solution of Example 1 for $\alpha=\beta=0.5$ and $\gamma=1$.

The authors apologize for any inconvenience caused to the readers. The change does not affect the scientific results. The manuscript will be updated and the original will remain online on the article webpage.

\section{References}

1. Thabet, H.; Kendre, S.; Chalishajar, D. New Analytical Technique for Solving a System of Nonlinear Fractional Partial Differential Equations. Mathematics 2017, 5, 47. [CrossRef]

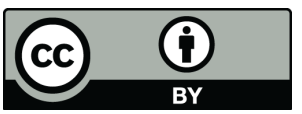

(C) 2018 by the authors. Licensee MDPI, Basel, Switzerland. This article is an open access article distributed under the terms and conditions of the Creative Commons Attribution (CC BY) license (http:/ / creativecommons.org/licenses/by/4.0/). 